\title{
Clinical Performance of Intramedullary Nailing system for Tibia Fractures: A Retrospective study
}

\author{
Prashant Kumar ${ }^{1,2 *}$, Mohit Kumar, ${ }^{1,2}$, Gaurav Luthra ${ }^{1}$ \\ ${ }^{1}$ Regulatory Department, Auxein Medical Pvt. Ltd., Sonipat, Haryana, India. \\ ${ }^{2}$ Auxein Medical Pvt. Ltd., Sonipat, Haryana, India.
}

*Corresponding author: Prashant Kumar, Regulatory Department, Auxein Medical Pvt. Ltd., Sonipat, Haryana, India.

Received date: March 11, 2020; Accepted date: June 15, 2021; Published date: June 19, 2021

Citation: P Kumar, M Kumar, G Luthra. (2021) Clinical Performance of Intramedullary Nailing system for Tibia Fractures: A Retrospective study. International Journal of Clinical Case Reports and Reviews. 7(3); DOI: 10.31579/2690-4861/124

Copyright: () 2021 Prashant Kumar, This is an open-access article distributed under the terms of the Creative Commons Attribution License, which permits unrestricted use, distribution, and reproduction in any medium, provided the original author and source are credited.

\begin{abstract}
Background: The tibia, or shinbone, is the common fracture long bone in body. There are two option includes, reamed and unreamed of surgical treatment of fractures. Reamed nailhas some advantage but they significantly harmful the endosteal circulation. Unreamed nail surplus the endosteal circulation but provide a less stable fixation. Afterward, because of ability to lock the nail proximally and distally, closed intramedullary nailing turned into an acknowledged treatment for closed shaft cracks during the ninth decade.
\end{abstract}

Aim: The main objective is to treat the tibia fractures by implanting the Intramedullary nailing system (Interlocking cannulated tibia nail and Expert tibia nail) manufactured by Auxein Medical Private Limited, Sonipat, India.

Material and Methods: In this retrospective study, studied the results of intramedullary tibianail in treatment of tibia fracture. A total of 25 consecutive patients were included in this study (11male, 14 female and average age 42.9 years). Fracture type was classified as per the Muller AO classification of fracture.

Results: The outcomes of clinical treatment were obtained in our study; No pain (92\%), Mildpain (8\%) after 2 year follow up. The follow up of patients were taken on 4-week, 1-year, 2-year according to VAS score. Paired $\mathrm{t}$ test was performed for statistical data analysis using Minitab and values of $\mathrm{p}<.05$ were taken to indicate significant value with confidence interval of $95 \%$. No implant related problem have been found like loosening, bending, corrosion etc.

Conclusion: Our outcomes with interlocking cannulated and Expert tibial interlocking nailing are empowering and exhibit the advantages of new nailing framework. It has been concluded that intramedullary tibia nailing system is best method for treatment of tibiafracture with good results and outcomes.

Keywords: tibia fracture; AO classification; expert tibia nail; interlocking cannulated tibia nail

\section{Introduction}

The seriousness of the crack typically relies upon the amount of force that caused the break and has mechanical points of interest with its bigger potential distances across and bigger surface-territory contact between the bone and nail [1-3]. To reduce the complications associated with conservative treatment, tendency towards operative management of tibial fractures is in vogue. Various operative methods like open reduction and plating, intramedullary nailing and external fixation, have their own indications, advantages anddisadvantages [4-5].

The ordinary advancement in intramedullary nailing of tibial fractures was the introduction ofmodern implants like the Expert Tibial Nail and Interlocking cannulated tibia nail. In these new implants the interlocking bolts can be introduced just below the tibia plateau, enabling the surgeon to treat very proximal tibial fractures with intramedullary nailing.

The Expert Tibial Nail System (ETNS) and Interlocking cannulated tibia nail, an intramedullary nailing framework is shown for breaks in the tibial shaft just as for metaphyseal and certain intraarticular cracks of the tibial head and the pilon fracture. Notwithstanding the standard static and dynamic locking choices, the ETNS highlights multi directional securing choices in the distal and proximal piece of the nail. End top blocks the most proximal screw making an angular stable construct.

Nicoll [6] 1974 showed that with preservationist treatment the likelihood of deferred association with comminuted fracture is $15 \%$, dislocated crack $27 \%$. Crack with extreme delicate tissue damage $12 \%$ and gap more than $1 \mathrm{~cm}$ is $65 \%$. Additionally, there is a $25 \%$ occurrence of residual joint stiffness and muscle shortcoming. The troubles that may emerge in 
the treatment of fracture of shaft of tibia incorporate - a high rate of open and tainted fracture as tibia lies externally just underneath the skin and an inclination of Redis placement of the sections when swelling downside, especially in slanted and winding fractures.

Afterward, because of potential to lock the nail proximally and distally, closed intramedullarynailing turned into an acknowledged treatment for closed shaft cracks during the ninth decade (Kuntscher, 1958) [7]. Anyway, symptoms of customary reaming-strategy had been noted likely because of mechanical, thermal and natural variables debilitating the endosteal blood supply (Pfister et al, 1979; Klein et al, 1990). Great outcomes had been appeared by utilizing locking nails for both closed and Gustilo grade I open cracks (Gustilo and Anderson, 1976; Kfemn and Broner, 1986; Court - Brown et al, 1990; Hooper et al, 1991) [8-10].

The main objective is to treat the tibia fracture by implanting the Intramedullary tibia nail system (Interlocking cannulated tibia nail and Expert tibia nail) manufactured by Auxein Medical Pvt. Ltd., Sonipat, India. The present study has been taken to feedback the results of fractures of tibia treated with Interlocking cannulated tibia and Expert tibia nail.

\section{Materials and Method}

This retrospective study was organized at Mesoamerica University, Quetzaltenango, Guatemala from Aug 2016 to Oct 2018, clinical data were collected for patients who received intramedullary tibia nailing system. A total of 25 consecutive patients meeting the inclusion exclusion criteria were included in this study.

\section{Inclusion Criteria}

1. Male or Female, skeletally mature patient above 18 years.

2. Tibia bone fracture

\section{Exclusion Criteria}

The participant may not enter the study if any of the following apply:

1. Subject having any neuromuscular disorder which would create an unacceptable riskof fixation failure or complications in postoperative care.

2. Subjects with substance abuse/alcohol issues.

3. Subjects who are incarcerated or have pending incarceration

4. Subject having infection local to the operative site.

5. Any uncontrolled systemic disease that, in the opinion of the Investigator, would preclude participation in the study (e.g., unstable medical status including uncontrolled elevated blood pressure, cardiovascular disease, and glycemic control) orput the subject at risk due to study treatment or procedures.

6. Subject with rapid joint disease, bone absorption, osteopenia, and/or osteoporosis.

7. Subject having suspected or documented metal allergy or intolerance.

The indications for surgery were Tibia bone Fracture. Intramedullary Tibia Nailing System (Auxein Medical Private Limited, Sonipat, Haryana, INDIA) were used for Tibia bone union.Patient physical fitness was also observed through America Society of anesthesiologist (ASA) Grade before undergoing surgery. The pain VAS is a unidimensional proportion of pain intensity [11], which has been generally utilized in differing grown-up populaces, incorporating those with rheumatic maladies [12-15]. Pain scale was recorded from patients according VAS score on 4 Week, 6-month, 1 year and 2 year follow up.

The intramedullary tibia nailing system (Interlocking cannulated tibia nail, Expert tibia nail)(Figure 1,2) is made of Titanium alloy (Ti6Al4V) and stainless steel (316L), and 4.5mm locking bolt for interlocking cannulated tibia nail, $4.4 \mathrm{~mm}$ locking bolt for Expert tibia nail, $4.8 \mathrm{~mm}$ locking bolt for expert tibia nail were used for fixation of implant.

The surgery was performed under general anesthesia, all patients go through a two-stage conversion from circular external fixation to internal fixation with Intramedullary cannulated and Expert tibia nail (Auxein Medical Private Limited, Sonipat, Haryana, India). After the removal of external fixator, local skin cut and soft tissues curettage was presented around the pin sites. The leg was fixed in a cast. Clinical outcomes were introduced through the 10-point scale info system named as VAS score. By using radiography (X-ray), the performance of implant was evaluated. X-ray was observed at follow up time showing good position of implant. $\mathrm{X}$-ray report were used for inspected bony union, non-union, implant failure and plate migration.

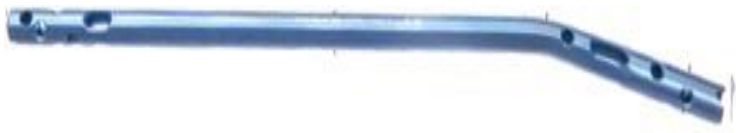

Figure 1: Interlocking Cannulated Tibia nail

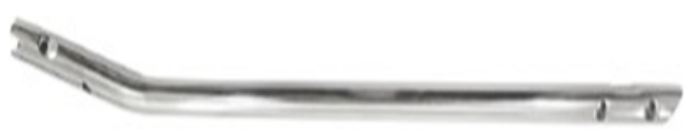

Figure 2: Expert Tibia nail

\section{Results}

In the study 25 patients were operated with Intramedullary Tibia Nailing System. There were 14 females and 11 males. Female patients were more susceptible in the study. The youngest patient in our series was 20 years and the oldest 61 years. The average age of the patient was

42.9 years as shown in. In this study, fracture classification has been recorded using AO Classification into 42-A1, 42-A2, 42-B1, 42-B2 and 42-A3 where 8 patients had 42-A1 type fracture while 8 patients had 42A2 type fracture and 6 patients had 42-B1 type fracture, 2 patient had 42B2 type fracture and 1 patient had 42-A3 type fracture in the Tibia bone as shown in table 2 .

\begin{tabular}{|c|c|}
\hline \multicolumn{2}{|c|}{ DEMOGRAPHICS } \\
\hline Sample Size & 25 \\
\hline Mean Age & 42.9 years \\
\hline & SEX \\
\hline Male & $11(44 \%)$ \\
\hline Female & $14(56 \%)$ \\
\hline \multicolumn{2}{|c|}{ FRACTURE CLASSIFICATION } \\
\hline
\end{tabular}




\begin{tabular}{|c|c|}
\hline $42-\mathrm{A} 1$ & $8(32 \%)$ \\
\hline $42-\mathrm{A} 2$ & $8(32 \%)$ \\
\hline $42-\mathrm{A} 3$ & $1(4 \%)$ \\
\hline $42-\mathrm{B} 1$ & $6(24 \%)$ \\
\hline $42-\mathrm{B} 2$ & $2(8 \%)$ \\
\hline & \\
\hline Fall from height & 3 \\
\hline Road accident & 4 \\
\hline Sport Injury & 3 \\
\hline Slip and fall & 6 \\
\hline Accident from two-wheeler & 9 \\
\hline
\end{tabular}

Table 2: Demography Data

The most common etiology of injury was fall from height, slip and fall, road accident and sports. All the patients were assessed according to ASA Grade before the surgical process.

Patients were followed up on 1 month, 6 months, 1 year and 2 year after the discharge. Bone Union had been achieved at 16 week means 4 Months from the day of surgery, it has been confirm through radiological examination by the Independent investigator, as per surgeon clinical union was defined as visible callus bridging the fracture in at least three cortices in radiographs and the patients could use their tibia without significant pain or weakness. All were the medical complications occur after surgery. Pain has been also recorded for each patient at their respective visits through Visual Analog Scale, the average pain scale at 4 Week was 5.4, and at 6-months was 4.44, 1.9 in 1 year and 0.62 after 2 year with p value >.05. Though the change of mean VAS score was statistically significant; it can be caused by short follow up time and less sample size. According to Visual Analog Scale system 92\% patient had showed no pain, and 8\% patients had showed mild pain as shown in table 3. No implant related complications have been found like implant loosening, bending, corrosion, related size issue, etc.

\begin{tabular}{|l|c|c|c|c|c|c|}
\hline \multirow{2}{*}{ Follow-up Time } & \multicolumn{7}{|l|}{ Number of Patients } \\
\cline { 2 - 7 } & No pain & Mild Pain & Nagging & Distress & Intense & $\begin{array}{l}\text { Worst } \\
\text { Possible }\end{array}$ \\
\hline 1- month & 0 & 3 & 22 & 0 & 0 & 0 \\
\hline 6- month & 0 & 0 & 19 & 6 & 0 & 0 \\
\hline 1- year & 8 & 17 & 0 & 0 & 0 & 0 \\
\hline 2- year & 23 & 2 & 0 & 0 & 0 & 0 \\
\hline
\end{tabular}

Table 3: Result of VAS score

\begin{tabular}{|c|l|c|c|c|c|}
\hline Sample & N & Mean & StDev & SE Mean & p-value \\
\hline Follow up (week) & 4 & 47.5 & 43.3 & 21.6 & .146 \\
\hline VAS score & 4 & 3.1 & 2.2 & 1.1 & \\
\hline
\end{tabular}

Table 4: Paired t test statistical analysis values with $95 \%$ confidence interval

\section{Discussion}

A biomechanical study indicated that the expansion of two proximal angled screws altogether improved the dependability of the intramedullary obsession build contrasted with the first methodology with obsession as in proximal tibia the medullary cavity is wide causing a lot ofunsteadiness which included the utilization of two transverse screws obsession.
The study lasted for one year and eight months starting from August 2016 to October 2018. 25 cases were taken for the examination during this period. As compared Ramesh Chand Meena et al. study of Intramedullary nailing versus proximal plating in the management of closed extra-articular proximal tibial fracture: a randomized controlled trial took 53 patients divided into cases and controls which is comparable to our sample size of our study. [17] 


\begin{tabular}{|c|c|c|c|c|}
\hline Objective & Nailing/Plating & $\begin{array}{l}\text { Fracture } \\
\text { size }\end{array}$ & Results & References \\
\hline $\begin{array}{l}\text { To evaluate the Effectiveness of } \\
\text { intramedullary nailing in } \\
\text { proximal third tibiafractures } \\
\text { done under image guidance for } \\
\text { nailing proposed by various } \\
\text { authors. }\end{array}$ & 34 & 34 & $\begin{array}{l}60 \% \text { cases had excellentresult. } \\
32 \text { out of } 34 \text { patients revealed } \\
\text { fracture union with no major } \\
\text { complication. }\end{array}$ & [16] \\
\hline $\begin{array}{l}\text { To compare plating and nailing } \\
\text { system in proximal tibia } \\
\text { fracture. }\end{array}$ & $22 / 22$ & 58 & $\begin{array}{l}\text { Union rate in the IMN groupwas } \\
94.7 \text { and that in the PTP group } \\
\text { was } 96 \% \text {. }\end{array}$ & [17] \\
\hline $\begin{array}{l}\text { To contrast } \\
\text { the effectiveness of } \\
\text { closed reduction and expert } \\
\text { tibia nailing and open } \\
\text { reduction and plate and screw } \\
\text { fixation in treat two tibial } \\
\text { fracture. }\end{array}$ & $31 / 22$ & 53 & $\begin{array}{l}\text { Result was excellent in 18cases, } \\
\text { good in } 10 \text { cases and fair in } 3 \\
\text { cases in ETN group (100\% } \\
\text { excellent-good rate). }\end{array}$ & [18] \\
\hline $\begin{array}{l}\text { Clinical evaluation of reamed } \\
\text { intramedullary nail to treat the } \\
\text { unstable fractureof tibia. }\end{array}$ & $24 / 18$ & 134 & $\begin{array}{l}\text { In closed fractures, there were } 2 \\
\text { superficial }(2 \%) \text { and } \\
3 \text { deep }(3 \%) \text { infections; in open } \\
\text { fractures there was } 1 \text { superficial } \\
(3 \%) \text { and } 7 \text { deep }(21 \%) \\
\text { infections. }\end{array}$ & [19] \\
\hline $\begin{array}{l}\text { To compare theIntramedullary } \\
\text { expert tibianailing with } \\
\text { percutaneous Locked } \\
\quad \text { Plating of Extra- } \\
\text { Articular ProximalTibial } \\
\text { Fractures. }\end{array}$ & $20 / 19$ & 39 & $\begin{array}{l}77 \% \text { union rate were } \\
\text { achieved. }\end{array}$ & {$[20]$} \\
\hline
\end{tabular}

Table 1: Different comparative study on tibia fracture and nailing system

Another study Ding-Chuan Zhu et al. studied Comparison of closed reduction and expert tibial nailing with open reduction and plate and screw fixation in the treatment of two segmental tibial fractures with sample size of 53 cases divided into cases and control [18]. Wiss et.al. 1995 studied the unstable fracture of tibia treated with a reamed intramedullary interlocking nail with 42 sample size [19].

Using the demographic data of patients, there is a medium named as VAS score that can decide the standard of surgical results and the factor to be adapted to make it successful. Considering pain scores and comparing the VAS outcome of different studies that also includes demographic data as well as biomechanics under controlled trials can be sufficient torecommend the treatment plans [21]. As for the present study the trial was conducted after one month, six-month, one year and 2 year. The outcome was presented by calculating the VAS score. This has shown good acceptance outcomes.

Using the present study represents the treatment of tibia fractures surgically by using Intramedullary tibia nailing system (Interlocking cannulated tibia nail and Expert tibia nail), which are designed and manufactured by Auxein Medical Pvt. Ltd, India. Major complications like nerve palsy and infection has been reported by many studies but none was reflected in the outcome of our evaluation. The major constrained of this study was the less sample size and patients' compliances in some cases like follow up time and hygiene.

\section{Conclusion}

From this study, we concluded that the intramedullary tibia nailing system is the best treatment for tibia fracture but it could be possible after counting the VAS score, AOclassification, and sample size. It has been also considered a better surgical option as it offers significant in terms of motion, blood loss, mean operating time, hospital stay, full weight bearing time, and union time. The fixation of tibia nail by cannulated bolt provide the superior stability properties in the clinical setting.

\section{Acknowledgements}

Not applicable

\section{Declaration}

Funding: No funding sources

Conflict of interest: None declared

Ethical approval: There is no need of ethical approval in retrospective study.

\section{References}

1. Bach AW, Hansen ST. Jr. (1989) Plates Vs external fixators in severe open Ribial fractures. Arandomized trial clin-orthop. 241:89-94.

2. Finkemeier CG, Schmidt AH, Kyle RF, Templeman DC, Varecka TF. (2000) A prospective, randomized study of intramedullary nails inserted with and without reaming for the treatment of open and closed fractures of the tibial shaft. J Orthop Trauma. 14:187-93.

3. Bonnevialle P, Bellumore Y, Foucras L, Hézard L, Mansat M. (2000) Tibial fracture with intact fibula treated by reamed nailing. Rev Chir Orthop Reparatrice Appar Mot.86:29-37.

4. Brown PW, Urban JG. (1969) Early weight bearing treatment 
of open fractures of the tibia. An end result study of 63 cases. J. bone and joint surg. 51-A:59-75.

5. Puno RM, Teynor JT. Nagano, Junji An Gustilo, R.B. (1986) Critical analysis of results of treatment of 201 tibial shaft fractures. Clin. Orthop. 212:113-121.

6. Nicoll EA. (1974) Closed \& open management of tibial fractures. Clin Orthop.

7. Kuntscher GBG. (1958) The Kuntscher method of intramedullary fixation. JBJS40A.

8. Gustilo, Anderson. (1976) Prevention of infection in 1025 open fractures of long bones. J.B.J.S. 58(4);453-458.

9. Klemn, Borner. (1986) Interlocking nailing of complex fracture of femur and tibia. Clin Orthop. 212:89.

10. Hooper GJ, Keddell RG, Penny ID. (1991) Coservative management of closed nailing for tibial shaft fracture. A randomized prospective trial. J Bone Joint Surg. 73(1):83-85.

11. McCormack HM, Horne DJ, Sheather S. (1988) Clinical applications of visualanalogue scales: a critical review. Psychol Med. 1007-1019.

12. Huskisson EC. (1974) Measurement of pain. Lancet; 2:11271131.

13. Downie WW, Leatham PA, Rhind VM, Wright V, Branco JA, AndersonJA. (1978) Studies with pain rating scales. Ann Rheum Dis. 37:378-381.

14. Huskisson EC, Wojtulewski JA, Berry H, Scott J, Hart FD, Balme HW. (1974) Treatment of rheumatoid arthritis with fenoprofen: comparison withaspirin. 1:176-180.

15. Berry H, Huskisson EC. Treatment of rheumatoid arthritis. Clin TrialsJ; 19724:13
16. Khayas Omer K, Arun K, Ravikumar V. et al. (2016) Outcomes of regular nailing in fracture of proximal third tibia shaft. IJOS. 2(3):142-148.

17. Meena RC, Meena UK, Gupta GL, Gahlot N, Gaba S. (2015) Intramedullary nailing versus proximal plating in the management of closed extra-articular proximal tibial fracture: a randomized controlled trial. Journal of Orthopaedics and Traumatology. 16(3):203.

18. Zhu DC, Liu L, Gao F, Li Q, Zhang B. (2015) Comparison of closed reduction and expert tibial nailing with open reduction and plate and screw fixation in the treatment of two segmental tibial fractures. Chinese Journal of Traumatology. 18(4):219222.

19. Wiss DA, Stetson WB. (1995) Unstable Fractures of the Tibia treated with a Reamed Intramedullary Interlocking nail. Clin Orthp. 315:56-63.

20. Lindvall E, Sanders R, Dipasquale T, Herscovici D, Haidukewych G, Sagi C. (2009) Intramedullary nailing versus percutaneous locked plating of extra-articular proximal tibial fractures: comparison of 56 cases. J Orthop Trauma. 23:485492.

21. Zarezadeh, A., Mamelson, K., Thomas, W.C., Schoch, B.S., Wright, T.W. and King, J.J. (2018) Outcomes of distal humerus fractures: What are we measuring? Orthopaedics \& Traumatology: Surgery \& Research. 104(8); 1253-1258. 